\title{
Sustained Growth in the Model of Overlapping Generations*
}

\author{
ERIC O'N. FISHER \\ Department of Economics, Cornell University, Ithaca, New York 14853-7601
}

\begin{abstract}
This paper analyzes endogenous economic growth in the model of overlapping generations. There is no bequest motive, nor are there any externalities. If the technology is convex, per capita growth can occur only if the economy has at least two sectors. This paper shows that the limiting marginal efficiency of investment determines the potential for growth and that the rate of growth depends upon the share of the capital stock devoted to investment. Sustained consumption growth can occur only under a fairly restrictive set of assumptions. There is an equilibrium with growth only if the marginal propensity to save is sufficiently high.
\end{abstract}

\section{INTRODUCTION}

Conventional theories of economic growth typically involve analyses of economies that do not grow. These theories commonly examine economies with maximal sustainable capital-labor ratios and describe paths of capital accumulation. It is unfortunate that any economy converging to a steady state is one in which per capita consumption is arbitrarily near a constant after finitely many periods. This is an unusually gloomy vision of the future, even for the dismal science.

This simple observation has sparked the recent interest in models of economies that actually do grow. An important vein in this literature involves models in which there are increasing returns to scale; Romer's [8] work is path-breaking. A second area in this research uses models in which there are no production non-convexities. This approach is appealing because it obviates the need to distinguish between scale cconomies that are internal to the firm and those that are external to it. The work of Rebelo [7], Jones and Manuelli [5], and Boldrin [2] is noteworthy.

* The author was a visiting assistant professor at the University of Chicago when this work was begun. He thanks an anonymous referee for useful suggestions, Larry Jones and Tapan Mitra for several helpful conversations, and seminar participants at the University of Indiana, University of Chicago, Ohio University, Northwestern University, and Cornell University for their comments. 
If an economy grows, then its capital stock must become unbounded. If the economy exhibits per capita growth, then labor eventually becomes a scarce factor and its renumeration grows without bound. If agents actually take advantage of the productive capacity of their economy, then consumption grows without bound. If agents save in order to acquire an everincreasing capital stock, then the level of savings may become unbounded. Hence an analysis of such economies involves dealing with several variables that tend towards infinity.

The easiest way of dealing with these arithmetic complexities is to use a discounting technique that makes the present values of streams of endogenous variables comparable. It may be appropriate to consider sequences of rewards that are dominated by a sequence that converges, and it is possible then to describe the trajectory of the economy in terms of laws of motion that are dependent upon parameters describing preferences and technology. This is the approach that Jones and Manuelli [5] use, and it involves sums of infinite sequences.

We use a different approach. Because we use the simplest model of overlapping generations, agents make quite uncomplicated decisions, using very little (decentralized) information. They know the real wage and the real interest rate during the one period in which they must choose anything. Since they do not value leisure for its own sake, they make the simple decision of how much to save. In a model of overlapping generations, the entire stock of capital must turn over in every period. Here is the rub. Is it possible for each generation to purchase the entire stock of capital that the economy has acquired?

The answer to this question is "no" in the simple one-sector model. This was shown by Jones and Manuelli [6] and Boldrin [2]. The intuition is simple. In a one-sector model, consumption and investment are perfect substitutes. Wages grow as the economy grows, but they do not grow as rapidly as the capital stock because the aggregate production function is concave. Hence, sooner or later, there will be a generation that will not be able to purchase the economy's stock of capital. But this implies that the economy will never get very large. So it cannot really grow.

Jones and Manuelli [6] analyze a two-sector model to show that such an economy can grow. They use a version of a model developed by Rebelo [7]. In a two-sector model, the terms of trade between investment and consumption can move against the investment good. Even if the physical stock of capital becomes arbitrarily large, its value in terms of a consumption good may stay within bounds.

The purpose of this paper is to examine the general structure of economies that grow when agents do not live forever. In such an economy, there is always an agent who will witness the sale of the economy's stock of capital during her life. The model below highlights this idea with a 
vengeance. One agent is endowed with nothing but the initial stock of capital; every other agent is endowed with nothing but her own labor. A young worker uses wages to consume, invest, and acquire the entire stock of capital. An old agent, having nothing but the capital she has acquired, is truly a member of the classe rentière, financing consumption solely from rentals income and from the proceeds of the sale of capital. In order for economic development to occur, every generation must go through this chain of events. This imposes considerable structure on the technologies of economies that can grow.

In order to summarize the introductory discussion and to acknowledge a deep dept, we state:

PRoposition 0. Assume that an economy's technology is convex, If there is only one sector and agents live only finitely many periods, then there can be no endogenous growth.

Proof. See Jones and Manuelli [6, Sect. 3] or Boldrin [2, Sect 2].

The rest of this paper consists of five other sections. Section 2 sets out the model. Section 3 analyzes the conditions under which growth is possible. Section 4 shows how the growth rate depends upon the share of capital devoted to the investment sector, and Section 5 shows how equilibrium growth depends upon the savings behavior of workers. Section 6 presents our conclusions.

\section{THe MOdeL}

There are two sectors in the economy. Each sector is characterized by a production function that is homogeneous of degree one in its inputs. It is helpful to think of the first sector as producing a consumption good and the second sector as producing an investment good. The production functions are:

$$
Q_{i}=F_{i}\left(K_{i}, L_{i}\right),
$$

where $K_{i}$ and $L_{i}$ are the inputs of capital and labor respectively in sector $i \in\{1,2\}$. We make the following assumptions about the economy's technology

Assumption 1. $\quad F_{i}: \mathbb{R}_{+}^{2} \rightarrow \mathbb{R}_{+}$is concave. $F_{i}(0,0)=0$, and $F_{i}\left(K_{1}, L_{1}\right)$ is smooth, ${ }^{1}$ homogeneous of degree one, and not decreasing in either argument.

\footnotetext{
${ }^{\prime}$ We define derivatives at the boundary of $\mathbb{R}_{+}^{2}$ using sequences in the interior of the domain of $F_{l}$.
} 
We use the simplest demographic structure possible to illustrate the notion of decentralized per capita growth, the model of overlapping generations. There is one agent born in each period; this agent lives for two periods only. There is one "old" agent who is alive at the beginning of the economy, and she lives for only one period. Each agent $t \geqslant 1$ is endowed with one unit of labor in her youth and nothing else. The old agent is endowed with the economy's initial capital stock $K_{1}>0$ and nothing else. Note that the economy has a constant labor supply in every period.

Increments to the stock of capital occur through production in the investment sector. The law of motion for the capital stock is

$$
K_{t+1}=(1-\delta) K_{t}+F_{2}\left(K_{t, 2}, L_{t, 2}\right),
$$

where $K_{t}$ is the capital stock at time $t, \delta \in(0,1]$ is the depreciation rate, $K_{t, 2}$ is the amount of capital used in the investment sector at time $t$, and $L_{t, 2}$ is the amount of labor used in that sector at that time. Note that the economy must produce some of the second good if it wants to add to its stock of capital. Output of the consumption good at time $t$ is

$$
Q_{t, 1}=F_{1}\left(K_{t, 1}, L_{i, 1}\right)
$$

where the variables are analogous. The resource constraints are:

$$
K_{t, 1}+K_{t, 2} \leqslant K_{t} \quad \text { and } \quad L_{t, 1}+L_{t, 2} \leqslant 1 \text {, }
$$

where we see again that the supply of labor is constant.

Agent $t \geqslant 0$ has preferences summarized by utility function $u_{0}\left(c_{0,1}\right)$ or $u_{t}\left(c_{t, i}, c_{t, t+1}\right)$, where $c_{t, s}$ is consumption by agent $t$ at time $s$; we state some weak assumptions about preferences in Section 5.

We can now define an equilibrium for this economy. Consider a sequence of goods prices and factor prices,

$$
\left\{\left(P_{t, 1}, P_{t, 2}, w_{t}, r_{t}\right)\right\}_{t=1}^{\infty},
$$

where $P_{t, i}$ is the price of good $i, w_{t}$ is the wage rate, and $r_{t}$ is the rentals rate, all at time $t$. Now let agent $t$ 's wealth be $W_{t}$. Then agent 0 chooses $c_{0,1}$ to maximize

$$
u_{0}\left(c_{0,1}\right)
$$

subject to

$$
P_{1,1} c_{0,1} \leqslant W_{0}
$$

and

$$
0 \leqslant c_{0,1} \text {, }
$$


and agent $t \geqslant 1$ chooses the pair $\left(c_{t, t}, c_{t, t+1}\right)$ to maximize

$$
u_{t}\left(c_{t, t}, c_{t, t+1}\right)
$$

subject to

$$
\begin{gathered}
P_{t, 1} c_{t, t}+P_{t+1,1} c_{t, t+1} \leqslant W_{t}, \\
0 \leqslant c_{t, t},
\end{gathered}
$$

and

$$
0 \leqslant c_{t, t+1} \text {. }
$$

Since agent 0 is endowed with nothing but the initial stock of capital, $W_{0}=r_{1} K_{1}+P_{1,2}(1-\delta) K_{1}$, and since agent $t \geqslant 1$ is endowed with nothing but one unit of labor, $W_{t}=w_{t}$

The firm's problem is also simple. Firm $i \in\{1,2\}$ chooses the pair $\left(K_{t, i}, L_{t, i}\right)$ to maximize

$$
P_{t, i} F_{i}\left(K_{t, i}, L_{t, i}\right)-r_{t} K_{t, i}-w_{t} L_{t, i} .
$$

Since $F_{i}\left(K_{i}, L_{i}\right)$ is linearly homogeneous, profits per period are zero, and (8) represents the maximization of the present value of firm $i$ 's profits.

We may define an equilibrium as a sequence (5) such that for all $t$

(i) agent 0 solves (6) and agent $t \geqslant 1$ solves (7);

(ii) firm $i$ solves (8);

(iii) $C_{t} \equiv c_{t, t-1}+c_{t, 1} \leqslant Q_{t, 1}$;

(iv) resource constraints (4) are satisfied;

(v) $K_{1}>0$ is given; and

(vi) $K_{t+1}$ evolves according to (2).

Note that we have defined aggregate consumption $C_{t} \geqslant 0$ in (iii). Condition (i) states that consumers maximize utility, (ii) states that firms maximize profits, (iii) is the material balances condition, (iv) are the resource constraints, (v) is the initial condition for the aggregate capital stock, and (vi) is its law of motion.

Since the production functions are linearly homogeneous, we can write them in intensive form. Let $k_{i}=K_{i} / L_{i}$ and $f_{i}\left(k_{i}\right)=F_{i}\left(K_{t} / L_{i}, 1\right)$. Assumption 1 implies that $f_{i}(\cdot)$ is positive, non-decreasing, and concave. Note that we have not assumed that $\lim _{k_{i} \rightarrow \infty} f_{i}^{\prime}\left(k_{i}\right)=0$. Since there is no population growth, we are examining the possibility of growth of per capita consumption. The only way that there can be sustained growth is for the capitallabor ratio to grow without bound. ${ }^{2}$

${ }^{2}$ Complex dynamics can arise in a two-sector model; see Boldrin [1]. 
Let $p_{t, 2} \equiv P_{t, 2} / P_{t, 1}$ be the real (current) price of a unit of the investment good after depreciation has occurred. Since $L_{t}=L_{t+1}=1$, the economy's capital-labor ratio is $k_{t+1}=K_{t+1}$, as given by (2). Then $p_{t, 2} k_{t+1}$ is the total cost of acquiring the economy's stock of the investment good at the end of period $t$. One can interpret $p_{t, 2}$ as the quantity of consumption a person born in period $t$ must give up in order to acquire a unit of the stock of capital at the end of her youth.

As long as investment is positive, it is appropriate to define the real interest rate in period $t+1$ by

$$
1+i_{t+1} \equiv p_{t+1,2}\left[1-\delta+f_{2}^{\prime}\left(k_{t+1,2}\right)\right] / p_{t, 2},
$$

where $k_{t+1,2}$ is the capital-labor ratio in the second sector in period $t+1$ and $f_{2}^{\prime}\left(k_{t+1,2}\right)$ is the marginal physical product of capital in that sector at that time. Equation (9) can be interpreted as stating that the current price of the investment good is the present value of the sum of next period's capital gains and net dividend.

As long as output of the consumption good is positive, profit maximization implies that the rentals rate satisfies

$$
r_{t}=f_{1}^{\prime}\left(k_{t, 1}\right)
$$

where $k_{t, 1}$ is the capital-labor ratio in the first sector in period $t$. Also, the wage rate satisfies

$$
w_{t}=f_{1}\left(k_{t, 1}\right)-k_{t, 1} f_{1}^{\prime}\left(k_{t, 1}\right)
$$

where all the variables are as above. Since agent $t \geqslant 1$ must acquire the stock of the investment good, it is necessary that

$$
w_{t} \geqslant p_{t, 2} k_{t+1}
$$

in order for equilibrium to obtain.

Equation (12) expresses the fundamental constraint that the assumption of finite lives places upon the possibility of growth. Wages must grow sufficiently rapidly to ensure that each successive generation can purchase the entire stock of capital in the economy. Since the capital-labor ratio cannot be bounded and capital is used in the production of the consumption good, wages will not be bounded. Whether real wages grow rapidly enough to buy an increasingly large stock of capital is the central limitation placed upon this economy. In a model with infinitely lived agents, investment plans are based upon the present value of the entire flow of income in the economy; in a model of overlapping generations, these plans are based upon the real value of each generation's endowment of labor. 
The economy's resource constraints are

$$
\lambda_{t, i} k_{t, 1}+\lambda_{t, 2} k_{t, 2}=k_{t},
$$

where $\lambda_{t, i}=L_{t, i} \in[0,1]$. Since $\lambda_{t, 1}+\lambda_{t, 2}=1, \lambda_{t, i}$ represents the proportion of the labor force employed in sector $i$ in period $t$. Hence, (2) is equivalent to

$$
k_{t+1}=(1-\delta) k_{t}+\lambda_{t, 2} f_{2}\left(k_{t, 2}\right),
$$

where we have used the linear homogeneity of $F_{2}\left(K_{2}, L_{2}\right)$. If $k_{1}$ is given, then the pair $\left(k_{t, 1}, k_{t, 2}\right)$ determines $k_{t+1}$ uniquely, since (13) is true under the assumption of full employment.

\section{Sustained Growth Paths}

Since we are not interested in the accumulation of capital for its own sake, it is appropriate to define sustained growth as an equilibrium in which the growth of aggregate consumption is eventually bounded away from zero.

Definition. Let $\left\{\left(P_{t, 1}, P_{t, 2}, w_{t}, r_{t}\right)\right\}_{t=1}^{\infty}$ support aggregate consumption $\left\{C_{t}\right\}_{t=1}^{\infty}$. There is sustained growth if and only if $\lim _{t \rightarrow \infty} \inf C_{t+1} / C_{t}>1$.

Note that this implies that the sequence $\left\{C_{r}\right\}_{r=1}^{\infty}$ is not bounded, Further, if there is sustained growth, then Assumption 1 implies that $\left\{K_{r}\right\}_{t=1}^{\infty}$ is not bounded and that $\lim _{t \rightarrow \infty}$ sup $K_{t+1} / K_{t}>1$, since $L_{t}=1$.

The analysis in this section focuses on the allocation of the capital stock between the two sectors of the economy and the asymptotic behavior of factor prices. Consider the marginal physical product of capital in the investment sector. In particular, let $\lim _{k_{2} \rightarrow \infty} f_{2}^{\prime}\left(k_{2}\right) \equiv b_{2} \geqslant 0$. We state

Propostrion 1. The economy displays sustained growth only if

$$
\begin{aligned}
& \text { (i) } \lim _{k_{1} \rightarrow \infty} f_{1}\left(k_{1}\right)=\infty ; \\
& \text { (ii) } \lim _{k_{2} \rightarrow \infty} f_{2}\left(k_{2}\right)=\infty \text {; and } \\
& \text { (iii) } \lim _{k_{2} \rightarrow \infty} f_{2}^{\prime}\left(k_{2}\right) \equiv b_{2} \geqslant \delta .
\end{aligned}
$$

Proof. Since $C_{r} \leqslant \lambda_{t, 1} f_{1}\left(k_{t, 1}\right)$ and $\lambda_{t, 1} \leqslant 1$, (i) is necessary for sustained growth.

We establish (ii) by contradiction. Assume that $f_{2}\left(k_{2}\right)$ is bounded from 
above by $B$. Then (2) implies that $K_{t+1}-K_{t} \leqslant B-\delta K_{t}$. Since $\delta>0$, $B-\delta K_{t}<0$ for large $K_{t}$. Hence $\left\{K_{t}\right\}_{t=1}^{\infty}$ is bounded. Since $C_{t+1}$ $\leqslant F_{1}\left(K_{t+1,1}, 1\right), C_{t+1}$ is bounded. This again implies no sustained growth.

We show (iii) again by contradiction. Assume that $b_{2}<\delta$. Since $f_{2}(\cdot)$ is concave, there is a $0<\widetilde{k}_{2}<\infty$ such that $f_{2}\left(k_{2}\right)<\delta \widetilde{k}_{2}$ for all $k_{2}>\widetilde{k}_{2}$. Then the argument follows that in (ii).

Proposition 1 is true even if $\lim _{k_{1} \rightarrow \infty} f_{1}^{\prime}\left(k_{1}\right)>\delta$. Hence, even if the marginal physical product of capital in the consumption sector is bounded above the rate of depreciation, the economy may not grow. It is the limiting behavior of the investment sector that determines the potential for growth.

It is convenient now to state

Proposition 2. If the economy displays sustained growth, $\lim _{t \rightarrow \infty}$ inf $p_{t, 2}$ $=0$.

Proof. Assume that the economy has sustained growth. Then Proposition 1 implies that there is a non-decreasing subsequence of $\left\{k_{t, 1}\right\}_{t=1}^{\infty}$ that is not bounded. Assume further that there is an $\varepsilon>0$ such that $p_{t, 2} \geqslant \varepsilon>0$ for all but finitely many $t$. It follows that there is a further non-decreasing subsequence of $\left\{k_{t, 1}\right\}_{t=1}^{\infty}$ satisfying $w_{t} / p_{t, 2} k_{t+1} \leqslant w_{t} / \varepsilon k_{t+1}$.

Assume first that $k_{t, 1} \leqslant k_{t} \leqslant k_{t, 2}$ for infinitely many $t$. For these $t$, (11) implies

$$
\begin{aligned}
w_{t} / \varepsilon k_{t+1} & =\left[f_{1}\left(k_{t, 1}\right)-k_{t, 1} f_{1}^{\prime}\left(k_{t, 1}\right)\right] / \varepsilon k_{t+1} \\
& \leqslant\left[f_{1}\left(k_{t, 1}\right)-k_{t, 1} f_{1}^{\prime}\left(k_{t, 1}\right)\right] / \varepsilon k_{t+1,1} \\
& \leqslant\left[f_{1}\left(k_{t, 1}\right)-k_{t, 1} f_{1}^{\prime}\left(k_{t, 1}\right)\right] / \varepsilon k_{t, 1},
\end{aligned}
$$

where the first inequality follows from the fact that $k_{t+1,1} \leqslant k_{t+1}$ and the second follows from the fact that $k_{t, 1} \leqslant k_{t+1,1}$ for this subsequence. But the concavity of $f_{1}(\cdot)$ also implies that $\lim _{t \rightarrow \infty}\left[f_{1}\left(k_{t, 1}\right)-k_{t, 1} f_{1}^{\prime}\left(k_{t, 1}\right)\right] / \varepsilon k_{t, 1}$ $=0$. Hence, for large $t, w_{t} / p_{t, 2} k_{t+1}<1$, which contradicts (12).

Proposition 1 also implies that there is a non-decreasing subsequence of $\left\{k_{t, 2}\right\}_{t=1}^{\infty}$ that is not bounded. Now assume that $k_{t, 2} \leqslant k_{t} \leqslant k_{t, 1}$ for infinitely many $t$. Then, for these $t$,

$$
\begin{aligned}
w_{t} / p_{t, 2} k_{t+1} & =\left[f_{2}\left(k_{t, 2}\right)-k_{t, 2} f_{2}^{\prime}\left(k_{t, 2}\right)\right] / k_{t+1} \\
& \leqslant\left[f_{2}\left(k_{t, 2}\right)-k_{t, 2} f_{2}^{\prime}\left(k_{t, 2}\right)\right] / k_{t+1,2} \\
& \leqslant\left[f_{2}\left(k_{t, 2}\right)-k_{t, 2} f_{2}^{\prime}\left(k_{t, 2}\right)\right] / k_{t, 2},
\end{aligned}
$$

where we have again used the fact that $k_{t, 2} \leqslant k_{t+1,2}$ for this subsequence. Since $f_{2}(\cdot)$ is also concave, this too contradicts $(12)$ for large $t$. 
The following Corollary is useful in Section 5. We state it here because it is a property of equilibrium, and it will help us in describing the savings behavior of the agents in a growing economy.

COROLLARY 2.1, If the economy displays sustained growth and $b_{2} \geqslant \delta$, then $i_{t+1} \leqslant b_{2}-\delta$ for infinitely many $t$.

Proof. Assume that the economy exhibits sustained growth. Let $\hat{p}_{t, 2} \equiv\left(p_{t+1,2}-p_{t, 2}\right) / p_{t, 2}$. Since (9) implies

$$
p_{t+1,2}=\left[p_{t, 2}\left(1+i_{t+1}\right)\right] /\left[\left(1-\delta+f_{2}^{\prime}\left(k_{t+1,2}\right)\right],\right.
$$

$\hat{p}_{t, 2}=\left[i_{t+1}+\delta-f_{2}^{\prime}\left(k_{t+1,2}\right)\right] /\left[1+f_{2}^{\prime}\left(k_{t+1,2}\right)-\delta\right]$. Since $f_{2}^{\prime \prime}\left(k_{t+1,2}\right) \geqslant b_{2} \geqslant \delta$, the denominator of this expression is positive. Since the economy has sustained growth, $\hat{p}_{t, 2} \leqslant 0$ for infinitely many $t$. Hence, $i_{t+1}+\delta-$ $f_{2}^{\prime \prime}\left(k_{t+1,2}\right) \leqslant i_{t+1}+\delta-b_{2} \leqslant 0$ for these $t$.

We may also state

Proposition 3. The economy displays sustained growth only if $\lim _{k_{1} \rightarrow \infty} f_{1}^{\prime}\left(k_{1}\right)=0$.

Proof. Assume that the economy displays sustained growth and that $\lim _{k_{1} \rightarrow \infty} f_{1}^{\prime}\left(k_{1}\right) \geqslant \varepsilon>0$. Proposition 1 implies that there is a non-decreasing subsequence of $\left\{k_{i, 2}\right\}_{t=1}^{\infty}$ that is not bounded. For this subsequence, factor market conditions imply that $p_{t, 2} \geqslant f_{1}^{\prime}\left(k_{t, 1}\right) / f_{2}^{\prime}\left(k_{t, 2}\right)$. Since $f_{1}(\cdot)$ is concave, $f_{1}^{\prime}\left(k_{t, 1}\right) / f_{2}^{\prime}\left(k_{t, 2}\right) \geqslant \varepsilon / f_{2}^{\prime}\left(k_{t, 2}\right)$. Since $\lim _{k_{2} \rightarrow \infty} f_{2}^{\prime}\left(k_{2}\right)=b_{2}, \lim _{t \rightarrow \infty} \inf p_{t, 2} \geqslant$ $\varepsilon / b_{2}>0$, contradicting Proposition 2 .

Remark. Let $K_{i}>0$. Since Assumption 1 states that $F_{i}\left(K_{i}, L_{i}\right)$ is smooth on $\mathbb{R}_{+}^{2}$, Propositions 1 and 2 imply that $F_{1}\left(K_{i}, 0\right)=0$ and that $F_{2}\left(K_{i}, 0\right)>0$. Hence, labor is essential in the production of the consumption good and labor cannot be essential in the production of the investment good.

In order to understand the restrictions that sustained growth places on the economy, consider the class of CES production functions. We state

Corollary 3.1. Let $f_{1}\left(k_{1}\right)=\left(c_{1} k_{1}^{\rho}+c_{2}\right)^{(1 / \rho)}$, with $\rho \leqslant 1, c_{1}>0$, and $c_{2}>0$. Then economy exhibits sustained growth only if $\rho=0$.

Proof. If $\rho>0$, then $f_{1}\left(k_{1}\right)$ is bounded and the economy does not display sustained growth. If $\rho<0$, then $\lim _{k_{1} \rightarrow \infty} f_{1}^{\prime}\left(k_{1}\right)>0$, contradicting Proposition 3.

Dasgupta and Heal [3, pp. 199-200] made a similar point in their study of exhaustible resources. Because labor is a fixed factor in a model that studies per capita growth, the consumption sector is on a knife-edge. The 
production function in that sector cannot be elastic, because labor's share goes to zero as the wage-rentals ratio rises, nor can it be inelastic, because then per capita output is bounded.

We can state an even more general result. Capital's share in the consumption sector is $\theta_{1}\left(k_{1}\right) \equiv k_{1} f_{1}^{\prime}\left(k_{1}\right) / f_{1}\left(k_{1}\right)$. Since $0 \leqslant \theta_{1}\left(k_{1}\right) \leqslant 1$, any sequence $\left\{\theta_{1}\left(k_{t, 1}\right)\right\}_{t=1}^{\infty}$ will have a convergent subsequence.

Proposition 4. The economy displays sustained growth only if $b_{2}>\delta$ and $\lim _{k_{1} \rightarrow \infty} \inf \theta_{1}\left(k_{1}\right)=\theta_{1}>0$.

Proof. Pick $\varepsilon>0$ and let $\lim _{k_{1} \rightarrow \infty} \inf \theta_{1}\left(k_{1}\right)=\theta_{1}$. Since $f_{2}(\cdot)$ is concave, (2) implies that there is $0<\widetilde{K}<\infty$ such that, for all $K_{1} \geqslant \widetilde{K}$, $K_{t+1} \leqslant K_{t}\left(1-\delta+b_{2}+\varepsilon\right)$. Hence, $K_{t+1} / K_{1} \leqslant\left(1-\delta+b_{2}+\varepsilon\right)$ for sufficiently large $K_{t}$. Since $f_{1}(\cdot)$ is concave, there is a non-decreasing sequence $\left\{C_{r}\right\}_{t=1}^{\infty}$ eventually satisfying

$$
C_{t+1} / C_{t} \leqslant 1+\theta_{1}\left(b_{2}-\delta+\varepsilon\right) .
$$

Proposition 1 implies that $b_{2} \geqslant \delta$. If $b_{2}=\delta$ this contradicts the definition of sustained growth since $\varepsilon$ was arbitrary. If $\theta_{1}=0$, this too contradicts the definition of sustained growth.

COROLlary 4.1. If the economy has sustained growth, then $\lim _{t \rightarrow \infty} \sup \lambda_{t, 1}=1$.

Proof. Let $\theta_{t, i} \equiv k_{t, i} \equiv k_{t, i} f_{t, i}^{\prime}\left(k_{t, i}\right) / f_{t, i}\left(k_{t, t}\right), \quad Y_{t} \equiv P_{t, 1} Q_{t, 1}+P_{t, 2} Q_{t, 2}$, $\theta_{t}^{i} \equiv P_{t, i} Q_{t, i} Y_{t}$, and $\theta_{t}^{L} \equiv w_{t} / Y_{t}$. Proposition 1 implies that $\lim _{t \rightarrow \infty} \sup \theta_{t, 2}$ $=1$ if the economy displays sustained growth. Further, Eq. (12) and Proposition 4 imply that $\theta_{t}^{L}$ is bounded away from zero. Since $\lambda_{t, i} \geqslant 0$ and $\lambda_{t, 1}+\lambda_{r, 2}=1$, the identity $\lambda_{r, i} \theta_{t}^{L} \equiv\left(1-\theta_{t, i}\right) \theta_{t}^{i}$ implies the result.

If the economy has sustained growth, the share of the labor force employed in the consumption sector has an accumulation point at one. Thus the investment sector is essentially linear in capital in the sense that $\lim _{t \rightarrow \infty}$ inf $\lambda_{t, 2}=0$ and $\lim _{k_{2} \rightarrow \infty} f_{2}^{\prime}\left(k_{2}\right)=b_{2}>0$ are both necessary for sustained growth.

Propositions 1, 2, 3, and 4 motivate the following postulate.

Assumption 2.

$$
\begin{aligned}
& \text { (i) } \lim _{k_{1} \rightarrow \infty} f_{1}^{\prime}\left(k_{1}\right)=0 \text {; } \\
& \text { (ii) } \lim _{k_{1} \rightarrow \infty} \inf k_{1} f_{1}^{\prime}\left(k_{1}\right) / f_{1}\left(k_{1}\right)=\theta_{1}>0 \text {; and } \\
& \text { (iii) } \lim _{k_{2} \rightarrow \infty} f_{2}^{\prime}\left(k_{2}\right)=b_{2}>\delta .
\end{aligned}
$$


Assumption 2(iii) distinguishes this economy from those in more conventional models in which it is often assumed that the asymptotic marginal physical product of capital is zero for every production activity. ${ }^{3}$ Assumption 2(ii) is a restriction that ensures that capital will always be sufficiently productive in the consumption sector. It is the only assumption that guarantees that the net growth rate of consumption be bounded away from zero.

The simplest production function that satisfies Assumptions 1 and 2(iii) is given $F_{2}\left(K_{2}, L_{2}\right)=b_{2} K_{2}$; indeed, any production function of the form $F_{2}\left(K_{2}, L_{2}\right)=b_{2} K_{2}+G_{2}\left(K L_{2}, L_{2}\right)$, where $G_{2}\left(K_{2}, L_{2}\right)$ itself is homogeneous of degree one, satisfies these assumptions.

We summarize the results of this section.

THEOREM 1. There is an economy with convex technology and finitely lived agents that has sustained growth. Such an economy has at least two sectors.

Proof. The existence of such an economy is demonstrated by Jones and Manuelli [6, Section 5]. The fact that the economy must have at least two sectors follows from Proposition 0 .

The following is also true.

THEOREM 2. Consider an economy with a convex technology satisfying Assumption 1. Assume that the agents live for only finitely many periods. If this economy exhibits sustained growth, then

(i) the limit of the marginal physical product of capital in the consumption goods sector is zero;

(ii) the limit of the marginal physical product of capital in the investment goods sector is greater than the rate of depreciation;

(iii) capital's share in the consumption sector does not approach zero.

Proof. This follows from Proposition 1, 2, 3, and 4.

The importance of Theorem 2 is that it shows that Jones and Manuelli [6] have given perhaps the simplest possible example of a convex economy in which agents live for finitely many periods and there still is sustained growth. They use a model in which $F_{1}\left(K_{1}, L_{1}\right)=K_{1}^{\theta_{1}} L_{1}^{1-\theta_{1}}$ and $F_{2}\left(K_{2}, L_{2}\right)=b_{2} K_{2}$. Their analysis was complicated slightly by the fact that agents were endowed with a unit of labor in each of the two periods of their lives, but such an assumption is not necessary.

Note that this economy has a fixed supply of labor and that the capital

${ }^{3}$ It is important to emphasize that Solow [11] did not impose this assumption uniformly in his seminal work. 
stock is produced in a sector that is asymptotically linear. This is indeed the simplest model that illuminates the nature of the problem under investigation. Such an economy was studied by Fel'dman $[4],{ }^{4}$ but he did not focus on interest rates and prices for obvious reasons.

\section{The Growth Rate}

We are interested in describing how rapidly an economy grows. Let $G_{t}=k_{t+1} / k_{t}$. Then we may define the gross rate of growth of the economy $G$ by

DEFINITION. $G \equiv \lim _{t \rightarrow \infty} \inf G_{t}$.

Note that the usual (net) growth rate is given by $g=G-1$. Now let $\kappa_{t, i}=K_{t, i} / K_{t}$ be the share of the capital stock used in sector $i$ at time $t$; note that $\kappa_{t, i} \in[0,1]$ and $\kappa_{r, 1}+\kappa_{t, 2}=1$. It is not surprising that $\kappa_{t, 2}$, the share of the capital stock in the investment goods sector, plays an important role in describing the growth rate of the economy.

We may state

Proposition 5. Assume that $0<k_{t}$, and let $\lim _{t \rightarrow \infty}$ inf $k_{t, 2}=\kappa_{2}$. Then

$$
G=1-\delta+b_{2} k_{2}
$$

Proof. Since $0<k_{t}$, Eq. (14) implies

$$
\begin{aligned}
k_{t+1} / k_{t} & =(1-\delta)+\lambda_{t, 2} f_{2}\left(k_{t, 2}\right) / k_{t} \\
& =(1-\delta)+\lambda_{t, 2}\left[f_{2}\left(k_{t, 2}\right) / k_{t, 2}\right]\left[k_{t, 2} / k_{t}\right] .
\end{aligned}
$$

Since $f_{2}(\cdot)$ is concave, $\lim _{t \rightarrow \infty} \inf \left[f_{2}\left(k_{t, 2}\right) / k_{t, 2}\right]=\lim _{t \rightarrow \infty} \inf f_{2}^{\prime}\left(k_{t, 2}\right)=b_{2}$. Note that $\lambda_{t, 2} k_{t, 2} / k_{t}=\left(L_{t, 2} / L_{t}\right)\left(K_{t, 2} / L_{t, 2}\right)\left(L_{t} / L_{t}\right)=K_{t, 2} / K_{t}$. The definitions of $\kappa_{2}$ and $G$ then imply (15).

Proposition 5 shows that the economy grows to the extent that the marginal physical product of capital in the investment sector is high. The economy also grows if a large share of the capital stock is used there. The rate of depreciation is a brake on growth. Note that Assumption 2 is not sufficient to ensure growth. The share of the capital stock in the investment sector depends upon the savings behavior of the economy, and we have not made explicit assumptions about the agents' preferences.

The most important implication of Proposition 5 is that $\lim _{t \rightarrow \infty}$ inf $\kappa_{t, 2}$ $\geqslant \delta / b_{2}$ is necessary for growth. Assumption 2 implies that $\delta / b_{2} \in(0,1)$;

${ }^{4}$ I thank Robert Becker for this helpful and erudite reference. 
hence, it is always possible for this economy to grow. It is not certain, however, that the agents will choose to grow. The key to ensuring growth is that agents' preferences are such that the share of the capital stock devoted to investment is sufficiently high. Even though growth is feasible if $b_{2}>\delta$, it may not supported as an equilibrium. If growth does occur, it may not be optimal. ${ }^{5}$ We turn our attention now to whether agents choose savings plans that allow for growth.

\section{EQUILIBRIUM GROWTH}

Recall that the agents' preferences are described by smooth utility functions $u_{0}\left(c_{0,1}\right)$ and $u_{t}\left(c_{r, 1}, c_{t, t+1}\right)$, where $c_{t, s}$ is consumption by agent $t$ at time $s$. We summarize the choices of agent $t \geqslant 1$ by the savings function $s\left(w_{t}, i_{t+1}\right)$, where the image set of this mapping is that of the non-negative real numbers. The value of $s\left(w_{t}, i_{t+1}\right)$ is the consumption agent $t$ forgoes in her youth. We assume

Assumption 3. The function $s: \mathbb{R}_{+} \times(-1,+\infty) \rightarrow \mathbb{R}_{+}$satisfies

(i) $s\left(w_{t}, i_{t+1}\right)$ is smooth; and

(ii) $0 \leqslant s\left(w_{t}, i_{t+1}\right) \leqslant w_{t}$.

It is possible to be this general because Theorem 3, the main result of this section, describes only a necessary condition for growth. Note that agents have identical preferences since they have the same savings function.

Corollary 2.1 is now handy because it implies that we can consider the limiting behavior of the savings function $s\left(w_{t}, i_{t+1}\right)$ on a restricted domain in which $i_{t+1} \leqslant b_{2}-\delta$. This upper bound is increasing in the net marginal efficiency of investment. Since the savings function is smooth, let $s_{1}\left(w_{t}, i_{t+1}\right)=\partial s\left(w_{t}, i_{t+1}\right) / \partial w_{t}$. Define $\Gamma \equiv 1-\delta+b_{2} ;$ since $1-\delta+f_{2}^{\prime}\left(k_{2}\right)$ converges to $\Gamma$, this is the limiting gross marginal efficiency of investment. Assumption 2 implies that $\Gamma>1$.

Proposition 6. Let $\lim _{w_{t} \rightarrow \infty} \partial s\left(w_{t}, i_{t+1}\right) / \partial w_{t}=s_{1}\left(i_{t+1}\right)$, and let Assumptions 1, 2, and 3 hold. If the economy displays sustained growth, then

$$
G=\left[\left(1-\theta_{1}\right) s_{1}\left(i_{t+1}\right)+\theta_{1}\right]^{-1} \Gamma\left(1-\theta_{1}\right) s_{1}\left(i_{t+1}\right),
$$

for some $i_{t+1} \leqslant b_{2}-\delta$.

${ }^{5}$ In a model of overlapping generations, the notion of an optimal consumption plan is subtle because there are infinitely many (dated) commodities and infinitely many agents. The interested reader will enjoy Shell [10]. 
Proof. Consider a non-decreasing subsequence of $\left\{k_{t, 2}\right\}_{t=1}^{\infty}$. Since the savings of agent $t$ purchase the economy's stock of capital,

$$
s\left(w_{t}, i_{t+1}\right)=p_{t, 2} K_{t+1} .
$$

Let $\widetilde{K}_{t, 1} \equiv K_{t}-K_{t, 2} / \theta_{t, 2}$; then (17) implies

$$
\left[\left(w_{t} / r_{t}\right)\left(s\left(w_{t}, i_{t+1}\right) / w_{t}\right)+\widetilde{K}_{t, 1}\right] / K_{t}=\left[1-\delta+f_{2}^{\prime}\left(k_{t, 2}\right)\right] / f_{2}^{\prime}\left(k_{t, 2}\right) .
$$

The right side of this expression converges to $\Gamma / b_{2}$.

Now consider the left side. Fix $i_{t+1}$; then $s\left(w_{t}, i_{t+1}\right) / w_{t}$ converges to $s_{1}\left(i_{t+1}\right)$, where we have used L'Hôpital's rule. Note that $w_{t} / r_{t}=\left(K_{t, 1} / L_{t, 1}\right)\left(1-\theta_{t, 1}\right) / \theta_{t, 1}$; Assumption 2 implies that $\left(1-\theta_{t, 1}\right) / \theta_{t, 1}$ has an accumulation point at $\left(1-\theta_{1}\right) / \theta_{1}$, and Corollary 4.1 implics that $\lim _{t \rightarrow \infty} \sup L_{t, 1}=1$. Since $\widetilde{K}_{t, 1} / K_{t}=1-\left(1-K_{t, 1} / K_{t}\right) / \theta_{t, 2}$ and $\lim _{t \rightarrow \infty} \theta_{t, 2}=1$, simple algebra shows that $K_{t, 1} / K_{t}$ has an accumulation point given by

$$
K_{t, 1} / K_{f}=\theta_{1}\left[\left(1-\theta_{1}\right) s_{1}\left(i_{t+1}\right)+\theta_{1}\right]^{-1}\left[\Gamma / b_{2}\right] .
$$

Note that (18) describes a balanced growth path for each $i_{t+1}$. The gross rate of growth implied by this path follows from (15).

The rage of growth is increasing in the marginal efficiency of investment and in the marginal propensity to save, corresponding to one's usual intuition.

The following corollary summarizes the implications of Proposition 6.

COROllary 6.1. Let $\lim _{w_{t} \rightarrow \infty} \partial s\left(w_{t}, i_{t+1}\right) / \partial w_{t}=s_{1}\left(i_{t+1}\right)$. If Assumptions 1,2 , and 3 hold and the economy displays sustained growth, then

(i) $\left[\left(1-\theta_{1}\right)\left(b_{2}-\delta\right)\right]^{-1} \theta_{1}<s_{1}\left(i_{t+1}\right)$ for some $i_{t+1} \leqslant b_{2}-\delta$;

(ii) $G \leqslant\left(1-\theta_{1}\right) \Gamma$; and

(iii) $\lim _{t \rightarrow \infty} \inf \left(1+i_{t+1}\right)=\Gamma / G^{1-\theta_{1}}$.

Proof. If the economy displays sustained growth, then $G>1$. Hence, (16) implies that (i) is true for some $i_{t+1} \leqslant b_{2}-\delta$.

Assumption 3 implies that $s_{1}\left(w_{t}, i_{t+1}\right) \leqslant 1$ for large $w_{t}$. Then (16) implies (ii).

Equation (9) implies that $1+i_{t+1}=\left[p_{t+1,2} / p_{t, 2}\right]\left[1-\delta+f_{2}^{\prime}\left(k_{t, 2}\right)\right]$. Consider non-decreasing subsequences $\left\{k_{t, i}\right\}_{t=1}^{\infty}$ constituting a balanced path growing at rate $G$. Then $p_{t+1,2} / p_{t, 2}$ converges to $G^{0_{1}-1}$, where we have used Assumption 2 and Corollary 4.1. The result follows from the fact that $1-\delta+f_{2}^{\prime}\left(k_{i, 2}\right)$ converges to $\Gamma$.

Part (i) of this corollary places a lower bound on the marginal propen- 
sity to save; this bound is decreasing in the marginal efficiency of investment, but it is still necessary to have sufficient savings to sustain growth. This is a point that Rostow [9] emphasized in his influential work. Part (ii) states that labor's share in the consumption sector has to be sufficiently high, and Part (iii) shows that the asymptotic interest rate is increasing in the marginal efficiency of investment and decreasing in the rate of growth of the economy. Corollary 6.1 implies that growth is efficient if it occurs.

The following is the main result of this paper.

THEOREM 3. Let Assumptions 1, 2, and 3 hold, and let $\Gamma$ be the limiting marginal efficiency of investment. Then sustained growth occurs only if $\Gamma$ $\left(1-\theta_{1}\right)>1$. It is further necessary that the limiting value of the marginal propensity to save satisfy

$$
\left[\left(1-\theta_{1}\right)\left(b_{2}-\delta\right)\right]^{-1} \theta_{1}<s_{1}\left(i_{i+1}\right),
$$

for some $i_{t+1} \leqslant b_{2}-\delta$, for the economy to exhibit sustained growth.

Proof. This follows from Propositions 5 and 6.

I consider Theorem 3 to be a fairly negative result. It shows that the simplest model in which there is convex technology with finitely lived agents exhibits sustained growth only under a restrictive set of assumptions. These assumption describe necessary relationships between the two sectors of the economy and put a lower bound on the limiting marginal propensity to save. ${ }^{6}$ Perhaps the most interesting implication of this section is that the conditions allowing for the possibility of sustained growth have to do with both the technology and the preferences of the economy describing the asymptotic balanced growth path.

\section{CONCLUSION}

We have examined the general structure of the simplest model of sustained consumption growth in which the technology is convex and agents live for only finitely many periods. Such an economy must have at least two sectors, and the terms of trade between the investment good and the consumption good must worsen. The rate of growth of the economy depends upon the marginal efficiency of investment and the share of capital devoted to investment. The investment sector is the "engine of growth" for

\footnotetext{
${ }^{6}$ If these periods correspond to 25 years, then a rough estimate of the marginal efficiency of investment in the United States would set $b_{2}-\delta=2$. Likewise, $\theta_{1}=\frac{1}{4}$ is plausible. Hence, Theorem 3 states that it is necessary that the limiting marginal propensity to save be greater than $\frac{1}{6}$ for that economy to grow.
} 
the economy; if the technology is convex, this sector must exhibit an asymptotically linear technology. This result is quite general; any growing convex economy must have a such a sector. A high marginal efficiency of investment will allow the economy to grow even if only a small share of the capital stock is devoted to investment.

This paper has not explored the conditions sufficient to ensure sustained growth in this model. One would need to place much more structure on the agents' savings behavior in order to describe these conditions fully. Still, there are preferences such that the economy will not grow, even if the marginal efficiency of investment is high.

\section{REFERENCES}

1. M. BOLDRIN, Paths of optimal accumulation in two-sector models, in "Economic Complexity: Chaos, Sunspots, Bubbles, and Nonlinearities" (W. Barnett et al., Eds.), pp. 231-252, Cambridge Univ. Press, Cambridge, 1990.

2. M. Boldrin, Dynamic externalities, multiple equilibria and growth, mimeo, Northwestern University, 1990.

3. P.S. Dasgupta and G. M. Heal, "Economic Theory and Exhaustible Resources," Cambridge Univ. Press, Cambridge, 1979.

4. G. A. FEL'DMAN, K teorii tempov narodnogo dokhoda, Planovoe khoziaistvo 11 (1928), 146-171; transl. as On the theory of growth rales of national income, I, in "Foundalions of Soviet Strategy [or Economic Growth" (N. Spulber, Ed.), pp. 174-199, Indiana Univ. Press, Bloomington, 1965.

5. L. E. Jones and R. MANUEldi, A convex madel of equilibrium growth, J. Polit. Econ. 98 (1990), 1008-1038.

6. L. E. Jones AND R. MANuell, "Finile Lifctimes and Growth," Research Paper No, 1092, Graduate School of Business, Stanford Univ., 1990.

7. S. T. RebeLo, Long-run policy analysis and long-run growth, J. Polit. Econ. 99, (1991), 500-521.

8. P. Romer, Increasing returns and long-run growth. J. Polit. Econ. 94 (1986), 1002-37.

9. W. W. Rosiow, "The Stages of Economic Growth: A Non-Communist Manifesto," Cambridge Univ. Press, Cambridge, 1960.

10. K. SHELl, Notes on the economics of infinity, J. Polit. Econ. 79 (1971), 1002-1011.

11. R. M. Solow, A contribution to the theory of economic growth, Quart. J. Econ. 70 (1956), 65-94. 